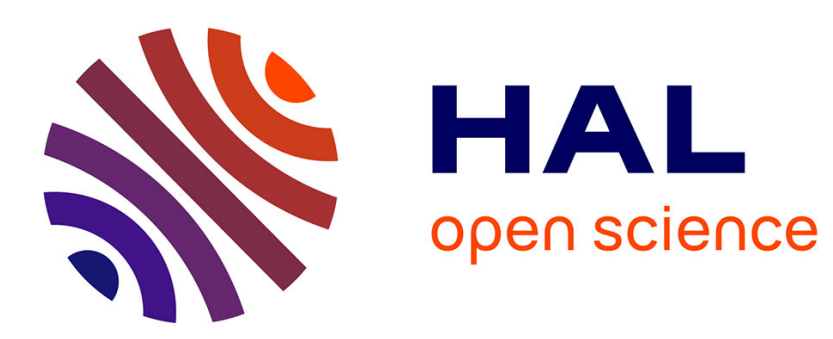

\title{
An Analysis of the Impact of Industrie 4.0 on Production Planning and Control
}

Uwe Dombrowski, Yannick Dix

\section{To cite this version:}

Uwe Dombrowski, Yannick Dix. An Analysis of the Impact of Industrie 4.0 on Production Planning and Control. IFIP International Conference on Advances in Production Management Systems (APMS), Aug 2018, Seoul, South Korea. pp.114-121, 10.1007/978-3-319-99707-0_15 . hal-02177883

\section{HAL Id: hal-02177883 \\ https://hal.inria.fr/hal-02177883}

Submitted on 9 Jul 2019

HAL is a multi-disciplinary open access archive for the deposit and dissemination of scientific research documents, whether they are published or not. The documents may come from teaching and research institutions in France or abroad, or from public or private research centers.
L'archive ouverte pluridisciplinaire HAL, est destinée au dépôt et à la diffusion de documents scientifiques de niveau recherche, publiés ou non, émanant des établissements d'enseignement et de recherche français ou étrangers, des laboratoires publics ou privés. 


\title{
An analysis of the impact of Industrie 4.0 on Production Planning and Control
}

Uwe Dombrowski and Yannick Dix

Institut for Advanced Industrial Management, Technische Universität Braunschweig, 38106

Braunschweig, Germany

$\{$ u.dombrowski, y.dix\}@tu-bs.de

\begin{abstract}
The Production Planning and Control of industrial companies is often based on an inaccurate data basis. The increasing availability and quality of data through the technologies and elements of Industrie 4.0 open up promising potentials for increasing efficiency. This paper presents the impacts of Industrie 4.0 technologies and elements on Production Planning and Control that have been studied by a deductive research design. Through a quantitative analysis of these impacts, an orientation for the choice of Industrie 4.0 technologies and elements is provided in order to support the planning activities of the PPC in a targeted manner.
\end{abstract}

Keywords: Production Planning and Control $\bullet$ logistics objectives $\bullet$ Industrie 4.0 - Digital Transformation

\section{Introduction}

With the aim of increasing competitiveness, manufacturing companies face the challenge to produce an increasing number of variants with a short delivery time and a high schedule reliability. These market challenges result in a significant increase in the complexity of planning and controlling the manufacturing process. Recent studies show that more than $2 / 3$ of the companies are not up to the future challenges of their Production Planning and Control (PPC) [1].

The technologies and elements of the Industrie 4.0 open up promising potentials to address these challenges [2,3]. Although the potentials of increasing data availability and data quality are obvious, the effects of Industrie 4.0 elements on the individual PPC modules and on the logistics objectives were not analyzed in detail. Based on a quantitative analysis, this article is intended to give an overview on this. 


\section{Production Planning and Control within the AIM reference model}

The reference model for the factory operation of the Institute for Advanced Industrial Management includes the Product Development Process and the Order Management Process [4]. The Production Planning and Control is assigned to the Order Management Process, which describes the planning, production, and sales of customer orders. The planning and controlling tasks of the PPC are group into several PPC modules. Figure 1 illustrates the classification of the PPC modules within the Order Management Process as well as the logical sequence of these modules to each other.

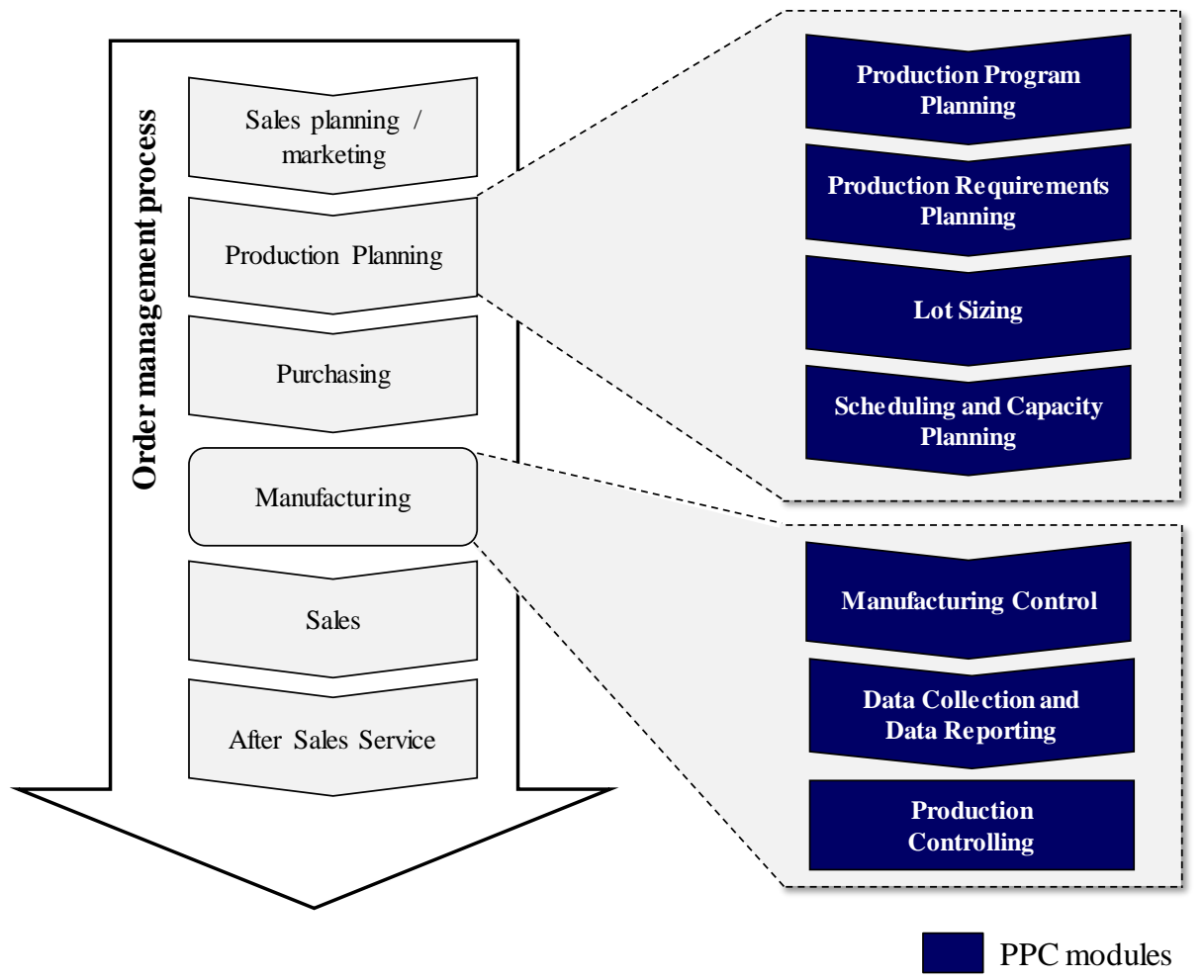

Fig. 1. Modules of Production Planning and Control

The Production Program Planning represents the starting point of the PPC. Based on past sales volumes and known customer orders, the production program is defined by quantity to be produced for every product and for every planning period [5]. The results of this task are documented in a sales plan, which contains the quantity of finished products (gross primary requirements). In the subsequent inventory planning, a stockholding strategy is developed. From the gross primary requirements of the product groups, the period-related net primary requirements (planned production quantity) are derived. For this purpose, the gross primary requirements are reduced by the not reserved inventories. 
Based on the net primary requirements, the Production Requirements Planning is responsible for calculating the required materials (dependent requirements). In this context, a distinction can be made between deterministic, stochastic, and heuristic requirements planning $[6,7]$.

In the Lot Sizing, the calculated net primary requirements of an article are aggregate into manufacturing orders considering the holding costs and ordering costs. The lot sizing can be carried out by static (e.g. EOQ formula), dynamic (e.g. Wagner-WhitinAlgorithm) and stochastic (e.g. order point inventory) methods [8, 9].

The Scheduling and Capacity Planning is responsible for determining the planned start dates and the planned completion dates of the operations. In addition, the task of Scheduling and Capacity Planning is to determine the capacity requirements for each planning period. First, a schedule is created by assigning planned start dates and planned completions dates to the individual operations. Subsequent capacity planning reviews the medium- and short-term realization of the previous planning results. For this purpose, the capacity demand induced by the schedule is compared to the available capacity. If a capacity overload is detected, a capacity alignment is required [10].

The Manufacturing Control includes the Order Generation and the Order Release [5]. This module transfers the planning results to manufacturing orders. In the case of make-to-order production, customer orders usually lead directly to an order generation in the amount of the requested quantity. On the other hand, if the company produces an order anonymously (make-to-stock production), the generation of an order takes place in the defined lot size according to an Order Generation Method. The Order Generation determines the planned input and planned output of the production. Finally, the orders are released by an Order Release Method. Considering the short-term availability of resources, the order release defines the time from which processing of a manufacturing order can start [10].

Through the Data Collection and Data Reporting, relevant manufacturing data for the PPC is recorded and reported back to a higher-level control system. The reported data forms the basis for the Production Controlling. By comparing target and current values (e.g. completion date of an order), adjustment requirements to the PPC can be identified, considering the strategic company objectives. Based on the reported data, the target times (e.g. throughput time for selected operations) can also be adjusted so that an improved data basis can be used in subsequent planning processes.

\section{Impact of Industrie 4.0 on Production Planning and Control}

The vision of Industrie 4.0 describes the real time, intelligent and digital networking of people, equipment and objects for the management of business processes and valuecreating networks [11]. The potential for PPC can generally be attributed to improved data availability and quality. Based on real-time data, for example, short-term interventions in the PPC can be made to counter events that are difficult to predict. In this context, it is already apparent that decision-making for short-term planning in particular can be supported by the use of Industrie 4.0 technologies. Furthermore, decisions that 
require a large number of input variables can be positively influenced by the improved data availability.

While the improved data availability and quality merely describe the potential for PPC in a general way, the influence of individual Industrie 4.0 technologies and elements on the PPC has not been comprehensively analyzed. So the question, which Industrie 4.0 technologies should be implemented, in order to support individual PPC modules, remains unanswered. Current use cases give an idea of the potential, but without discussing the success of the technologies used for the PPC modules. Likewise, the influences of these technologies on the logistics objectives are only superficially analyzed. In this context, it becomes apparent that the improved data availability and quality basically offers advantages, but the resulting potential for the production planning and control has so far only been insufficiently specified. Thus, in practice, the question arises as to how the improved data availability and quality can be translated into economic success in the form of precise and reliable planning results.

Although digitization is currently widely discussed in both science and economy, there is no consistent definition of the structure of Industrie 4.0 [12]. Against this background, the Bundesverband Informationswirtschaft, Telekommunikation und neue Medien e. v. (Bitkom) defines five technology fields (TF). The technology fields CyberPhysical Systems (1), Cloud Computing (2), Smart Factory (3), Robust Networks (4), and IT Security (5) are assigned individual Industrie 4.0 technologies [13]. Since this paper focuses on Production Planning and Control, it is expedient to limit the Industrie 4.0 model according to Bitkom. Because Robust Networks and IT Security do not reveal any direct potential for the PPC, this paper uses the technology fields of CyberPhysical Systems, Cloud Computing and Smart Factory. The technologies fields of the Robust Networks (broadband internet, mobile communications, mobile devices) and IT Security (data privacy, information security) form the basis for ensuring a high degree of reliability, availability and security for communication and data exchange between different IT systems. Both technology fields thus are the basis for Cyber-Physical Systems, Cloud Computing, and Smart Factory [14, 15].

Consequently, this paper focuses on the Industrie 4.0 elements listed in Table 1. In addition to [13], the technology field Cyber-Physical Systems was assigned the technology RFID (radio frequency identification). In order to be able to consider companyspecific enhancements of the ERP system, the technology field Smart Factory was supplemented by the element ERP Enhancement. 
Table 1. Chosen elements of Industrie 4.0 according to [13]

\begin{tabular}{|l|c|l|}
\hline Elements & TF & Explanation \\
\hline Sensors \& actuators & 1 & Controlling and moving an object or system \\
\hline RFID & 1 & Wireless and sightless identification of objects \\
\hline Networked objects & 1 & Objects with the ability to process and exchange data \\
\hline M2M $^{1}$-interaction & 1 & Exchange of information between machines with each other \\
\hline Visualization & 2 & Visualization of key performance indicators \\
\hline Virtualization & 2 & Integration of real objects in digital models \\
\hline HMI & 2 & User interface for interaction between human and machine / software program \\
\hline ERP Enhancement & 2 & Application-specific enhancement of the ERP system with digital instruments \\
\hline Real-time data & 3 & Collection and processing of data in real time \\
\hline Big Data & 3 & Analysis of large and unstructured datasets \\
\hline Apps & 3 & Applications on mobile devices to control the production \\
\hline
\end{tabular}

${ }^{1}$ machine-to-maschine, ${ }^{2}$ human machine interface

\section{$4 \quad$ Potential for the Production Planning and Control}

Based on current use cases, the potentials of Industrie 4.0 technologies and elements listed in Table 1 were analyzed for the separate PPC modules (Fig. 1). As this article focuses on the planning activities of the Production Planning and Control, the PPC modules Data Collection and Data Reporting and Production Controlling are not considered in detail below. While the Data Collection and Data Reporting includes all measures to collect production data and make it available at the place of processing [16], this paper is intended to answer the question as to which PPC module this data is beneficial for.

Thus, the focus is on the remaining PPC modules in order to show which Industrie 4.0 technologies and elements can be used to increase efficiency within the PPC. The database for this analysis is based on 38 application-related publications in prestigious journals from 2007 to 2017, whereby the focus was on publications in the field of Production Planning and Control. First, the required information for each PPC module was identified. Subsequently, the output variables of the listed Industrie 4.0 elements (Tab. 1) were collected and analysed through a literature search. Based on a matching of output variables (Industrie 4.0 element) and input variables (PPC module), the impact of an Industrie 4.0 element was derived for the corresponding PPC module. If a match between output variables and input variables could be determined, a positive impact was assumed. Otherwise, no effect was suspected between Industry 4.0 element and PPC module. Thus, real-time data (output: e.g. work in progress for each workstation) can help significantly increase order release efficiency, provided that it is aligned with bottleneck systems [5]. In this case, a positive impact on the module Manufacturing Control can be observed, since the order release is to be assigned to this module. Figure 
2 summarizes the results of this analysis. Depending on the PPC modules, the number of sources (y-axis) was plotted for each Industrie 4.0 element (x-axis), which indicates an increase in efficiency of the PPC modules.
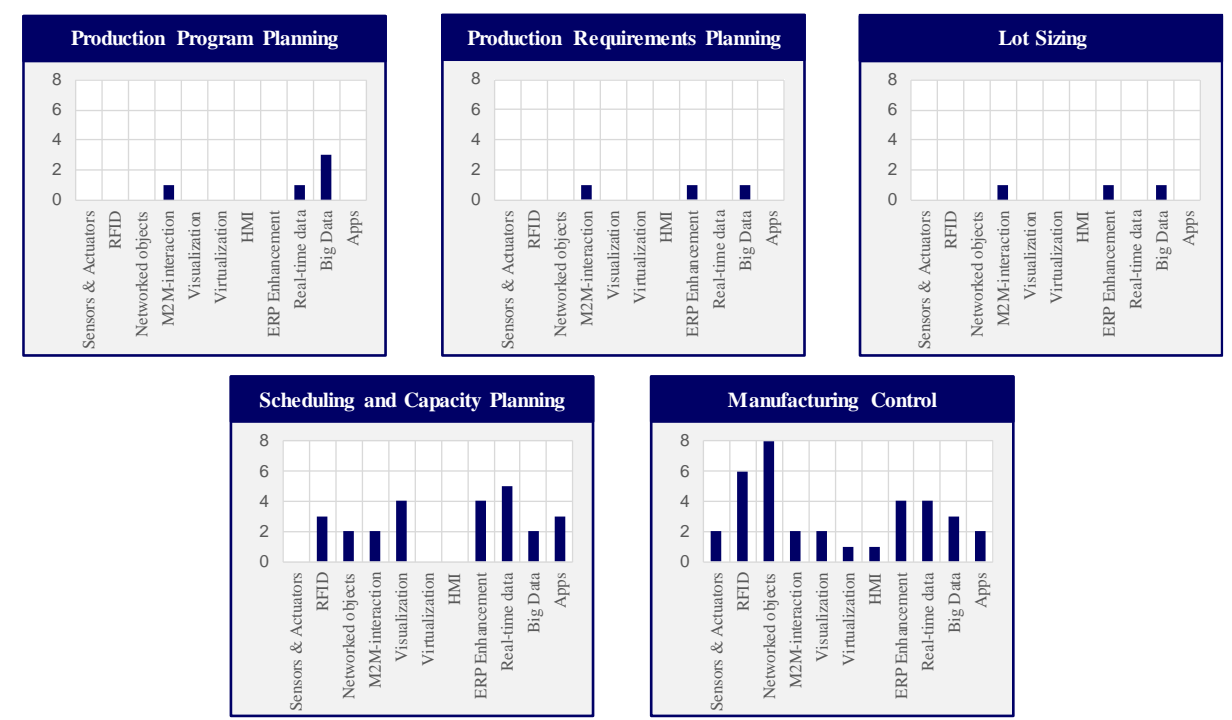

Manufacturing Control

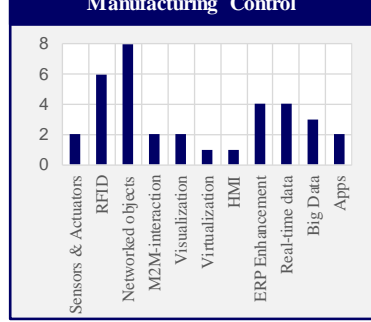

Fig. 2. Positive impact of Industrie 4.0 elements on PPC modules

It has been shown that Scheduling and Capacity Planning as well as Manufacturing Control can benefit significantly from the elements of the Industrie 4.0, because the decision making process for these planning activities is largely based on current production information. This information can be collected in particular by the elements Sensors \& Actuators, RFID and Networked objects. The relatively minor impact on the other modules is due to various characteristics. While Production Program Planning is strategic planning, Production Requirements Planning and Lot Sizing are based on simple mathematical operations, so that they have a low planning complexity. Therefore, no significant increases in efficiency can be achieved due to the improved data availability and quality of the Industrie 4.0 elements.

Based on this, the potential of an Industrie 4.0 element for improving logistics objectives was examined. An example in this context is an increase in schedule reliability by the use of networked objects. Considering their planned completion dates, subsequent operations and required resources, orders can dynamically prioritize themselves in front of a workstation. Because schedule reliability can be significantly influenced by the choice of a priority rule [5], networked objects can contribute to improving this logistics objective. A summary of the results is shown in Figure 3, whereby the representation is to be interpreted in analogy to Figure 2. 

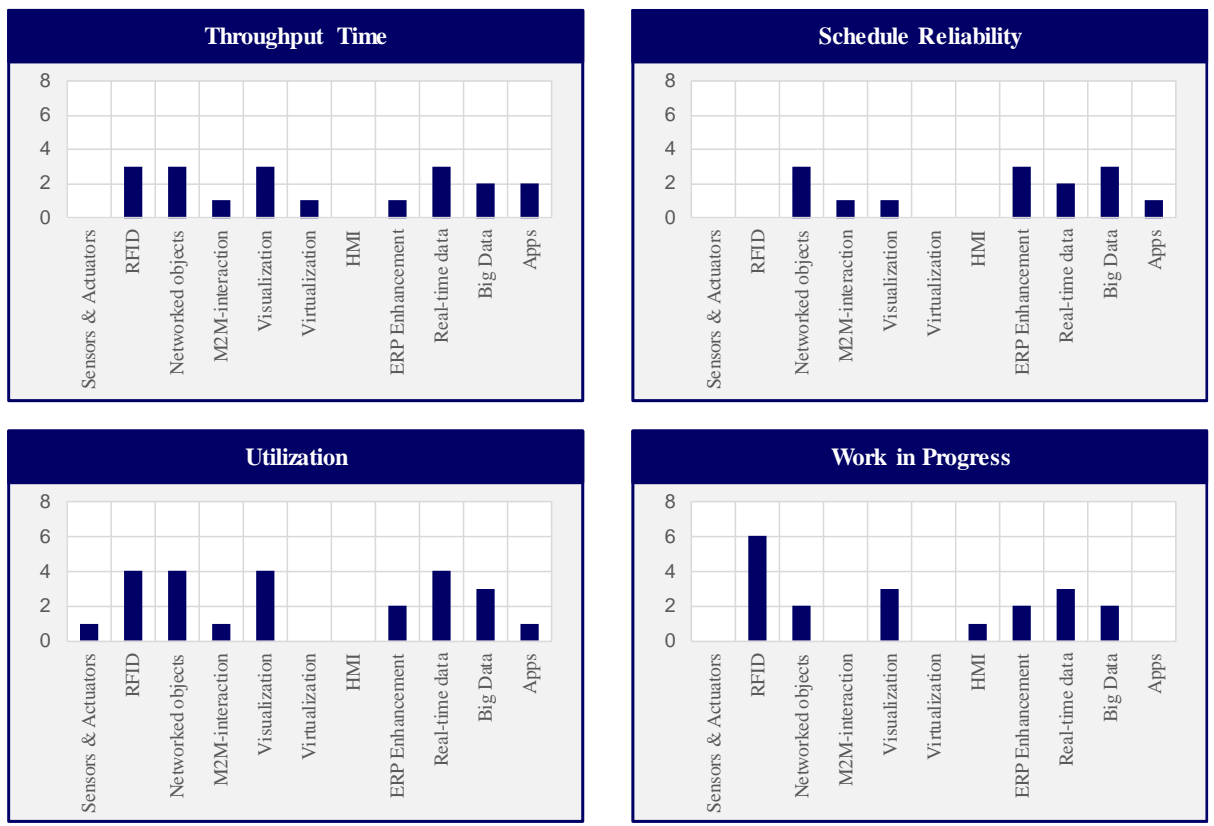

Fig. 3. Positive impact of Industrie 4.0 elements on logistics objectives

With regard to the improvement of logistics objectives by the use of Industrie 4.0 elements, there is consistently high potential. Because the logistics objectives can be significantly influenced by the operative control, this recognition can be traced back to the high potential of the Production Control (Fig. 2). Nevertheless, differences between the separate Industrie 4.0 elements can be identified.

\section{Summary}

Industrie 4.0 offers comprehensive potential for increasing efficiency in Production Planning and Control. So far, these potentials have only been reduced to the increasing availability and quality of data. Based on a quantitative analysis, this paper shows the potentials of Industrie 4.0 elements for the separate PPC modules as well as for the logistics objectives. With the aim of improving the planning quality of the PPC, this paper offers new perspectives.

The missing taxonomy of Industrie 4.0 has proved critical in the context of this article. If we consider that the elements of Cloud Computing (e.g. real-time data) require Cyber-Physical Systems (e.g. RFID), further research questions arise. On the one hand, the need for a consistent model to describe the structure and inherent dependencies of the elements can be derived. On the other hand, it seems appropriate to transfer the presented analysis to the processes of the PPC. Based on existing approaches [17], it is conceivable to describe the planning activities of the PPC in a process-oriented manner in order to evaluate the increase in efficiency on this basis. These results can be used to 
derive effective strategies for the Digital Transformation of the Production Planning and Control.

\section{References}

1. Nyhuis, P., Mayer, J., Pielmeier, J., Berger, C., Engehausen, F., Hempel, T., Hünnekes, P.: Aktuellen Herausforderungen der Produktionsplanung und -steuerung mittels Industrie 4.0 begegnen. PZH-Verlag, Garbsen (2016).

2. Nyhuis, P., Hübner, M., Quirico, M., Schäfers, P., Schmidt, M.: Veränderung in der Produktionsplanung und -steuerung. In: Handbuch Industrie 4.0 - Geschäftsmodelle, Prozesse, Technik, pp. 31-50. Carl Hanser Verlag, München (2017).

3. Erola, S., Sihna, W.: Intelligent production planning and control in the cloud - towards a scalable software architecture. 10th Conference on Intelligent Computation in Manufacturing Engineering. Flexible Automation and Intelligent Manufacturing Conference 2016, pp. 571-576 (2016).

4. Dombrowski, U.; Mielke, T. (eds.): Ganzheitliche Produktionssysteme - Aktueller Stand und zukünftige Entwicklung. Springer, Heidelberg (2015).

5. Lödding, H.: Handbook of Manufacturing Control - Fundamentals, Description, Configuration. Springer, Berlin (2013).

6. Wiendahl, H.-P.: Betriebsorganisation für Ingenieure. Carl Hanser, München (2008).

7. Magad, E. L., Amos, J. M.: Total Materials Management - Achieving Maximum Profits Through Materials/Logistics Operations. Springer, Boston (1995).

8. Haase, K.: Lotsizing and Scheduling for Production Planning. Springer, Heidelberg (1994).

9. Schneider, H.: Operative Produktionsplanung und -steuerung. Oldenburg, München (2005).

10. Wiendahl, H.-P.: Load-Orientated Manufacturing Control. Springer, Berlin (1995).

11. Dombrowski, U., Richter, T.: Supplementing Lean Production Systems with Information and Communication Technologies. 26th International Conference on Flexible Automation and Intelligent Manufacturing Conference, pp. 654-661 (2016).

12. Dombrowski, U., Richter, T., Krenkel, P.: Wechselwirkungen von Ganzheitlichen Produktionssystemen und Industrie 4.0. Zeitschrift für wirtschaftlichen Fabrikbetrieb, Vol. 112, Issue 6, pp. 430-433 (2017).

13. Bundesverband Informationswirtschaft, Telekommunikation und neue Medien e. V.: Industrie 4.0 - Volkswirtschaftliches Potenzial für Deutschland. Studie, Berlin (2014).

14. Kritenbrink, T.: Sicherheit in der Industrie 4.0 - Realitätscheck und Ausblick. Industrie 4.0 Management, Issue 4, pp. 29-32 (2017).

15. Baumer, S.: Verlässliche eingebettete Systeme für Industrie 4.0. Zeitschrift für wirtschaftlichen Fabrikbetrieb, Vol. 109, Issue 4, pp. 264 (2014).

16. Zäpfel, G.: Grundzüge des Produktions- und Logistikmanagements. Oldenburg Verlag, München (2001).

17. Schmidt, M., Schäfers, P.: The Hanoverian Supply Chain Model: modelling the impact of production planning and control on a supply chain's logistic objectives. Production Engineering, Vol. 11, Issue 4-5, pp 487-493 (2017). 